\title{
Down-regulation of ROBO2 Expression in Prostate Cancers
}

\author{
Youn Jin Choi • Nam Jin Yoo • Sug Hyung Lee
}

Received: 20 September 2013 / Accepted: 5 November 2013 / Published online: 24 November 2013

(C) The Author(s) 2013. This article is published with open access at Springerlink.com

\begin{abstract}
Several lines of evidence exist that axon guidance genes are involved in cancer pathogenesis. Axon guidance genes $R O B O 1$ and $R O B O 2$ are candidate tumor suppressor genes (TSG). The aim of our study was to address whether $\mathrm{ROBO} 1$ and $\mathrm{ROBO} 2$ expressions are altered in prostate cancers (PCA). In this study, we analyzed ROBO1 and ROBO2 expressions in 107 PCAs. In the immunohistochemistry, loss of ROBO2 expression was identified in $66 \%$ of PCAs and was significantly higher than that in normal cells $(p<0.001)$. By contrast, there was no significant difference of ROBO1 expression between normal and PCAs. Our results indicate that axon guidance protein $\mathrm{ROBO} 2$ is frequently lost in PCA and that $\mathrm{ROBO} 2$ might be involved in PCA pathogenesis as a candidate TSG.
\end{abstract}

Keywords $\mathrm{ROBO} 2 \cdot$ Prostate cancer $\cdot$ Expression

\section{Introduction}

Mounting evidence indicates that signaling pathways implicated in development are altered in tumorigenesis as well [1]. SLIT proteins bind ROBO proteins and are involved in axon guidance during development [2]. In addition, SLIT/ROBO interactions play important roles in many processes, including apoptosis, motility, angiogenesis and invasion of cancer cells [2]. For example, decrease of SLIT/ROBO interaction leads to loss of E-cadherin expression [3, 4]. ROBO1-deficient mice suffer from cancer development [5]. Axon guidance genes $\mathrm{ROBO} 1$ and $\mathrm{ROBO} 2$ are frequently lost in many cancers

Y. J. Choi $\cdot$ N. J. Yoo $\cdot$ S. H. Lee $(\bowtie)$

Department of Pathology, College of Medicine, The Catholic

University of Korea, 505 Banpo-dong, Socho-gu, Seoul 137-701,

South Korea

e-mail: suhulee@catholic.ac.kr (head/neck, breast, lung, kidney and uterine cancers), and considered tumor suppressor genes (TSG) in them [6-9]. In prostate cancers (PCA), mRNA expression of axon guidance genes were frequently altered [10]. ROBO1 mRNA expression was down-regulated compared with normal prostate tissues, while ROBO2 mRNA expression was not altered [10]. However, it remains unclear whether $\mathrm{ROBO} 1$ and $\mathrm{ROBO} 2$ expression is altered in PCA at protein level. In this study, we analyzed expression of ROBO1 and $\mathrm{ROBO} 2$ proteins in PCA tissues.

\section{Materials and Methods}

For this, tissue microarray (TMA) blocks containing normal and PCA tissues of 107 patients were used. The PCA were surgically resected 107 adenocarcinomas, and consisted of one Gleason score 5, 10 score 6, 47 score 7, 10 score 8 and 39 score 9 cancers. In addition, prostate intraepithelial neoplasia (PIN) were included in the TMA of 20 patients' specimens. Age of the patients ranged 43-77 years with an average of 67.6 years. Sizes of the cancers ranged $1.1-5.0 \mathrm{~cm}$ in diameter with an average of $2.5 \mathrm{~cm}$. Approval was obtained from the institutional review board for this study.

Using TMA tissue section series, immunohistochemistry for ROBO1 and ROBO2 were performed using ImmPRESS System (Vector Laboratories, Burlingame, CA, USA). Antibodies for human for ROBO1 (GeneTex, Irvine, CA, USA; dilution 1/400) and ROBO2 (Santa Cruz Biotechnology, Santa Cruz, CA, USA; dilution 1/50) were used as primary antibodies. After deparaffinization, heat-induced epitope retrieval was conducted by immersing the slides in Coplin jars filled with $10 \mathrm{mmol} / \mathrm{L}$ citrate buffer ( $\mathrm{pH} 6.0$ ) and boiling the buffer for $30 \mathrm{~min}$ in a pressure cooker (Nordic Ware, Minneapolis, MN, USA) inside a microwave oven at $700 \mathrm{~W}$; the jars were then cooled for $20 \mathrm{~min}$. Reaction products were developed with diaminobenzidine and counterstained with 
Fig. 1 Visualization of ROBO1 and $\mathrm{ROBO} 2$ expressions in prostate cancer tissues by immunohistochemistry. a Both normal prostate epithelial cells $(\mathrm{N})$ and cancer cells $(\mathrm{T})$ are positive for ROBO1 immunostaining. b A prostate cancer shows negative $\mathrm{ROBO} 2$ immunostaining in the cancer cells $(\mathrm{T})$, whereas normal epithelial cells $(\mathrm{N})$ are positive for ROBO2 immunostaining. c Another prostate cancer shows positive $\mathrm{ROBO} 2$ immunostaining in the cancer cells. d A PIN lesion shows negative $\mathrm{ROBO} 2$ immunostaining in the cells

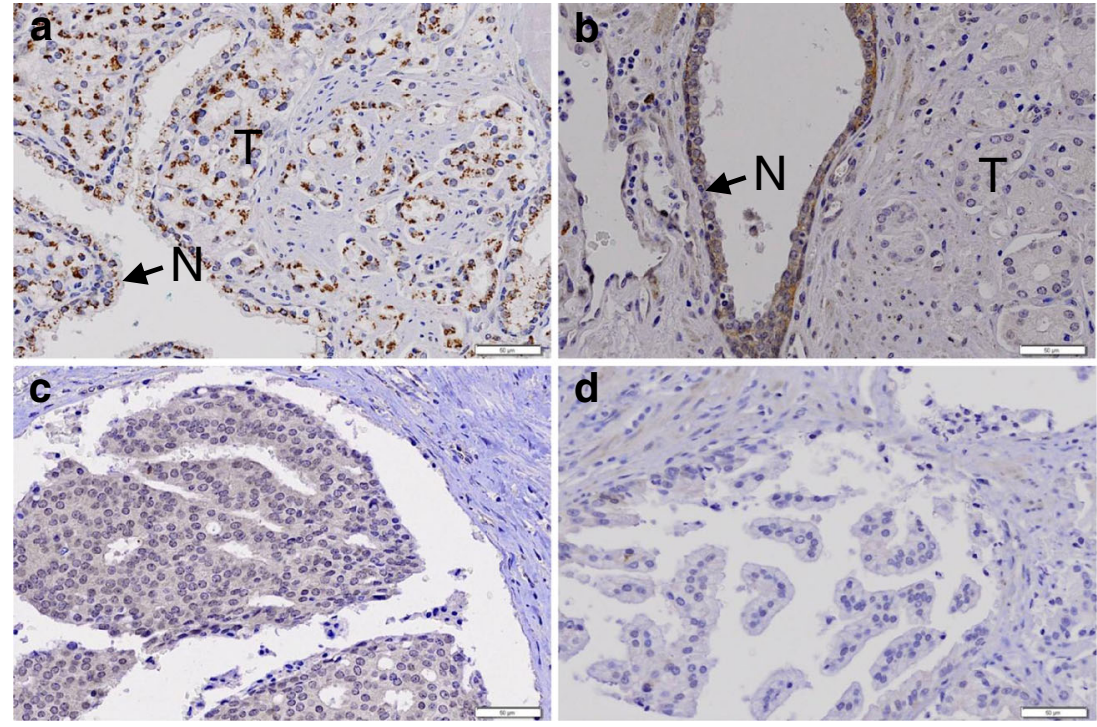

hematoxylin. Other procedures were performed as described previously [11-13]. Under light microscope, tumors were interpreted as positive when $20-100 \%$ of the cells showed moderate to intense cytoplasm and/or nuclear staining, and as negative when $0-19 \%$ of the cells showed staining by immunohistochemistry. The results were reviewed independently by two pathologists. As negative controls, a slide was treated by replacement of primary antibody with the blocking reagent. The immunostaining was judged to be specific by absence of consistent immunostaining of cells by replacement of primary antibody with the blocking reagent. Also, reduction of signal intensity was observed as dilution of the antibody was increased. For the statistical analysis of the immunohistochemical data, we used $\chi^{2}$ and Fisher's exact tests.

\section{Results and Discussion}

In the PCA, immunopositivity for ROBO1 was observed in $102(95 \%)$ of the 107 PCAs (Fig. 1a). Normal prostate glandular cells displayed positive ROBO1 immunostaining in all cases (Fig. 1a). There was no significant difference of ROBO1 expression between normal and PCA (Fisher's exact test, $p>0.05$ ). PIN lesions showed ROBO1 expression in all cases. By contrast, $\mathrm{ROBO} 2$ expression was positive only in 36 of the PCA (34\%), while normal prostate glandular cells displayed positive ROBO1 immunostaining in all cases (Fig. $1 \mathrm{~b}$ and c). ROBO2 expression in PCA was significantly higher than that in normal cells (Fisher's exact test, $p<0.001$ ). PIN showed ROBO2 expression in $40 \%$ of the cases (Fig. 1d). ROBO2 expression was significantly different between normal and PIN (Fisher's exact test, $p<0.001$ ), but not different between PCA and PIN (Fisher's exact test, $p>0.05$ ). Next, we analyzed relationship between $\mathrm{ROBO} 2$ expression and pathologic parameters (age, tumor size, vascular invasion,
Gleason score and stage). However, we were not able to find any significant association ( $\chi^{2}$ test, $p>0.05$ ).

Because a previous study [2] showed loss of ROBO1 protein in many cancer types and an earlier study [10] showed loss of ROBO1 mRNA expressed compared with normal prostate, we expected to find loss of ROBO1 in PCA. However, we found no difference of ROBO1 protein expression between normal and PCA tissues. Unexpectedly, however, we found that $\mathrm{ROBO} 2$ expression is lost in $2 / 3$ of the PCA. Our study also identified that PIN were negative for ROBO2 expression, suggesting that decrease of $\mathrm{ROBO} 2$ expression might occur at an early stage of PCA development. In addition to expressional alterations, somatic mutations of both $\mathrm{ROBOI}$ and $\mathrm{ROBO} 2$ have been reported in pancreatic cancers and fluke-associated cholangiocarcinomas [14, 15]. Recent whole-exome sequencing analyses identified neither $R O B O 1$ or $R O B O 2$ mutation in PCA [16, 17], suggesting that somatic mutation of $\mathrm{ROBO} 1$ and $\mathrm{ROBO} 2$ genes may be rare in PCA. In conclusion, our data suggest that loss of axon guidance molecule ROBO2, rather than ROBO1, might be involved in PCA tumorigenesis as a TSG.

Acknowledgments This study was supported by a grant from National Research Foundation of Korea (2012R1A5A2047939).

Open Access This article is distributed under the terms of the Creative Commons Attribution License which permits any use, distribution, and reproduction in any medium, provided the original author(s) and the source are credited.

\section{References}

1. Topczewska JM, Postovit LM, Margaryan NV, Sam A, Hess AR, Wheaton WW, Nickoloff BJ, Topczewski J, Hendrix MJ (2006) Embryonic and tumorigenic pathways converge via Nodal signaling: role in melanoma aggressiveness. Nat Med 12:925-932 
2. Mehlen P, Delloye-Bourgeois C, Chédotal A (2011) Novel roles for Slits and netrins: axon guidance cues as anticancer targets. Nat Rev Cancer 11:188-197

3. Tseng RC, Lee SH, Hsu HS, Chen BH, Tsai WC, Tzao C, Wang YC (2010) SLIT2 attenuation during lung cancer progression deregulates beta-catenin and E-cadherin and associates with poor prognosis. Cancer Res 70:543-551

4. Prasad A, Paruchuri V, Preet A, Latif F, Ganju RK (2008) Slit-2 induces a tumor-suppressive effect by regulating beta-catenin in breast cancer cells. J Biol Chem 283:26624-26633

5. Xian J, Clark KJ, Fordham R, Pannell R, Rabbitts TH, Rabbitts PH (2001) Inadequate lung development and bronchial hyperplasia in mice with a targeted deletion in the Dutt1/Robol gene. Proc Natl Acad Sci U S A 98:15062-15066

6. Mitra S, Mazumder-Indra D, Mondal RK, Basu PS, Roy A, Roychoudhury S, Panda CK (2012) Inactivation of SLIT2ROBO1/2 pathway in premalignant lesions of uterine cervix: clinical and prognostic significances. PLoS One 7:e38342

7. Sundaresan V, Chung G, Heppell-Parton A, Xiong J, Grundy C, Roberts I, James L, Cahn A, Bench A, Douglas J, Minna J, Sekido Y, Lerman M, Latif F, Bergh J, Li H, Lowe N, Ogilvie D, Rabbitts P (1998) Homozygous deletions at 3p12 in breast and lung cancer. Oncogene 17:1723-1729

8. Dallol A, Forgacs E, Martinez A, Sekido Y, Walker R, Kishida T, Rabbitts P, Maher ER, Minna JD, Latif F (2002) Tumour specific promoter region methylation of the human homologue of the Drosophila Roundabout gene DUTT1 (ROBO1) in human cancers. Oncogene 21:3020-3028
9. Ghosh S, Ghosh A, Maiti GP, Alam N, Roy A, Roychoudhury S, Panda CK (2009) Alterations of ROBO1/DUTT1 and ROBO2 loci in early dysplastic lesions of head and neck: clinical and prognostic implications. Hum Genet 125:189-198

10. Latil A, Chêne L, Cochant-Priollet B, Mangin P, Fournier G, Berthon P, Cussenot O (2003) Quantification of expression of netrins, slits and their receptors in human prostate tumors. Int J Cancer 103:306-315

11. Yoo NJ, Kim HR, Kim YR, An CH, Lee SH (2012) Somatic mutations of the KEAP1 gene in common solid cancers. Histopathology 60:943-952

12. Kim MS, Hur SY, Yoo NJ, Lee SH (2010) Mutational analysis of FOXL2 codon 134 in granulosa cell tumour of ovary and other human cancers. J Pathol 221:147-152

13. Kim MS, Oh JE, Kim YR, Park SW, Kang MR, Kim SS, Ahn CH, Yoo NJ, Lee SH (2010) Somatic mutations and losses of expression of microRNA regulation-related genes AGO2 and TNRC6A in gastric and colorectal cancers. J Pathol 221:139-146

14. Biankin AV, Waddell N, Kassahn KS et al (2012) Pancreatic cancer genomes reveal aberrations in axon guidance pathway genes. Nature 491:399-405

15. Ong CK, Subimerb C, Pairojkul C et al (2012) Exome sequencing of liver fluke-associated cholangiocarcinoma. Nat Genet 44:690-693

16. Berger MF, Lawrence MS, Demichelis F et al (2011) The genomic complexity of primary human prostate cancer. Nature 470:214-220

17. Barbieri CE, Baca SC, Lawrence MS et al (2012) Exome sequencing identifies recurrent SPOP, FOXA1 and MED12 mutations in prostate cancer. Nat Genet 44:685-689 